\title{
Arranjos configurados pelos nervos do plexo braquial no urubu (Coragyps atratus foetens - Linnaeus, 1758)
}

Pamela Rodrigues Reina MOREIRA ${ }^{1}$

Wilson Machado de SOUZA $^{2}$

Nair Trevisan Machado de SOUZA $^{2}$

Roberto Gameiro

CARVALHO ${ }^{2}$

Correspondência para:

Pamela Rodrigues Reina Moreira,

R. Ivo Simões Gomes, 665, Lagoinha,

14095-180, Ribeirão Preto-SP, pamela_rreina@yahoo.com.br

Recebido para publicação: 07/06/2005 Aprovado para publicação: 12/03/2009

1 - Pós-Graduanda em Medicina Veterinária (área de Patologia Veterinária) da Universidade Estadual Paulista, Jaboticabal-SP

2 - Curso de Medicina Veterinária da Universidade Estadual Paulista, Araçatuba-SP

\section{Resumo}

O estudo anatômico da origem e distribuição do plexo braquial no urubu (Coragyps atratus foetens) foi efetuado em 14 animais, adultos, machos e fêmeas oriundos da região de Araçatuba (SP). Após a fixação em solução aquosa de formaldeído a 10,00\%, realizou-se a dissecação bilateral da origem dos plexos braquiais e sua distribuição. A análise permitiu verificar, que o plexo braquial do urubu, possui quatro troncos, os quais originam-se dos ramos ventrais dos nervos espinhais cervicais onze (C11), doze (C12) e treze (C13) e dos ramos ventrais dos nervos espinhais torácicos um (T1) e (T2) em 100\% dos casos em ambos antímeros. O primeiro tronco parte de C11 nos antímeros direito e esquerdo, e da margem cranial do cordão dorsal partem os nervos subescapular, subcoracoescapular e supracoracóide; em ambos antímeros (100\%). O segundo tronco origina-se de C12 em ambos antímeros, dando origem ao cordão dorsal, dele partem os nervos axilar, radial e anconeal (100\%). O terceiro tronco do plexo origina-se unicamente de C13 (100\%) e o quarto tronco de T1 em ambos antímeros (100\%). Os troncos de C12, C13 e T1 unem-se dando origem ao cordão ventral, o qual partem os nervos medianoulnar que se divide em mediano e ulnar e os nervos peitorais (100\%). T2 emite filamentos que se unem à raiz nervosa de T1, sendo um filamento $(35,55 \%)$ e dois filamentos $(64,29 \%)$ no antímero direito, enquanto que no esquerdo um filamento $(42,85 \%)$, dois filamentos $(50 \%)$ e três filamentos $(7,15 \%)$.

\section{Introdução}

Os urubus são considerados como uma classe separada, porém em muitos aspectos, pouco distanciados do tronco geral dos répteis, de onde se originaram. Um fenômeno de preservação permitiu conhecer cinco esqueletos de uma ave ancestral, Archaeopteryx, o único representante da subclasse Archaeornithes, de sedimentos do final do Jurássico. Nesta ave ainda existiam dentes; as asas eram providas de dedos com garras e a longa cauda era semelhante à de um réptil. ${ }^{1,2,3}$

A poluição gradativa do meio é uma realidade preocupante dos tempos modernos. Em um ambiente naturalmente poluído as aves selvagens são indivíduos resistentes e participam ativamente das cadeias biológicas, determinando deste modo à necessidade de conhecimentos profundos de sua morfofisiologia. Sob esta vertente, o urubu exerce papel de fundamental importância na degradação de resíduos orgânicos e na possível difusão de agentes biológicos. $^{4}$

Desde a primeira edição de Nomina Anatomica Avium (NAA) ${ }^{5}$, somente alguns termos foram adicionados ou alterados neste capítulo. Entretanto, alguns termos 
foram atualizados e dados novos da literatura foram introduzidos. Duas revisões recentes, usando predominantemente a nomenclatura de $\mathrm{NAA}^{5}$, oferecem uma excelente introdução à Anatomia dos nervos cranianos e periféricos.

O plexo braquial dos animais tem sido objeto de vários estudos clínicos e cirúrgicos e nas aves a pesquisa destas estruturas deve-se ao fato de serem os seus componentes diretamente relacionados aos diagnósticos de disfunções neuromusculares, conseqüentes de processos traumáticos, infecções, neoplasias e infestações por ácaros e vírus, assim como sobre as características pós-morte dos músculos peitorais, como também pelos procedimentos anestésicos local ou regional, que objetivam potencializar o efeito analgésico durante o período pré e trans-operatório. $6,7,8,9,10,11,12,13,14,15,16,17,18$

Este trabalho teve como objetivo estabelecer a formação do plexo braquial do urubu (Coragyps atratus foetens), a origem dos nervos que o constitui, bem como a distribuição dos mesmos aos músculos na região da asa, descrevendo e sistematizando seus trajetos.

\section{Material e Método}

Foram utilizados 14 urubus (Coragyps atratus foetens), adultos, machos e fêmeas, procedentes da Região de Araçatuba (SP), capturados com a devida autorização do Ibama, (estes animais foram oriundos de um projeto, no qual se testou a toxina Botulínica para observar a sua resposta imunológica e por isso não puderam ser novamente soltos no ambiente, embora todos tenham sobrevivido à citada toxina) e após o óbito, com inalação de éter sulfúrico, os mesmos foram encaminhados ao Laboratório de Anatomia da UNESP, Campus Araçatuba, onde foram fixados mediante injeção de solução de formaldeído a $10 \%$ e mergulhados em cubas contendo essa mesma solução. Depois da fixação das peças, procedeu-se a dissecação mediante incisão, rebatimento do revestimento cutâneo e tela subcutânea da região axilar, secção transversal dos músculos peitoral superficial e profundo, próximo ao esterno e quilha, expondo e individualizando os nervos que compõem o plexo braquial, e isolamento das demais estruturas vasculares.

Os troncos nervosos foram individualizados próximos à coluna vertebral, com o intuito da observação dos ramos ventrais dos nervos espinhais cervicais e torácicos.

Após a identificação destes níveis, procedeu-se a dissecação dos nervos em sentido distal, observando bilateralmente a distribuição de ramos nervosos a cada músculo na região. Em seguida, os arranjos foram esquematizados e algumas preparações fotografadas para documentação. A nomenclatura utilizada neste trabalho está de acordo com a Nomina Anatomica Avium de $1993 .{ }^{19,20}$

\section{Resultados}

Após a dissecação, verifica-se que os plexos braquiais destes animais, em 100\% dos casos, apresentam quatro troncos, os quais originam-se dos ramos ventrais dos nervos espinhais cervicais situados na décima primeira (C11), décima segunda (C12) e décima terceira (C13) vértebras cervicais e dos ramos ventrais do primeiro (T1) e segundo (T2) nervo espinhais torácicos (Figuras 1 e 2).

Identifica-se constituindo o plexo braquial do urubu os seguintes nervos: subescapular, supracoracóide, subcoracoescapular, axilar, radial, anconeal, bicipital, medianoulnar (mediano e ulnar), cutâneo, peitorais craniais e caudais, torácico dorsal e ventral (Figuras 3 e 4).

Particularmente, quanto à formação e distribuição de cada nervo do plexo braquial do urubu, o qual é formado por quatro troncos que, após ultrapassar a parede do tórax, unem-se para formar dois cordões nervosos, o dorsal e o ventral. $\mathrm{O}$ primeiro tronco, origina-se tanto no antímero direito quanto no esquerdo, do décimo primeiro espaço intervertebral cervical (C11) em $100 \%$ dos casos. Os nervos subescapular, subcoracoescapular e supracoracóide em 14 


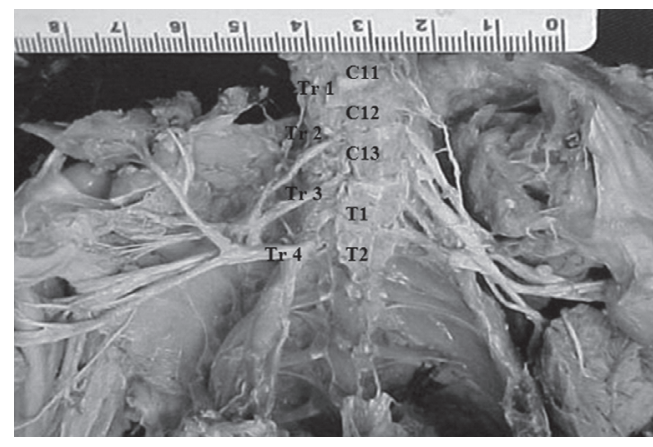

Figura 1 - Mostrando a origem dos nervos do plexo braquial no urubu (Coragyps atratus foetens), apresentando quatro troncos $(\mathrm{Tr} 1, \mathrm{Tr} 2, \mathrm{Tr} 3$ e $\operatorname{Tr} 4$ ), os quais originam-se dos ramos ventrais dos nervos espinhais cervicais situados na décima primeira (C11), décima segunda (C12) e décima terceira vértebras cervicais (C13) e dos ramos ventrais do primeiro (T1) e segundo (T2) nervos espinhais torácicos

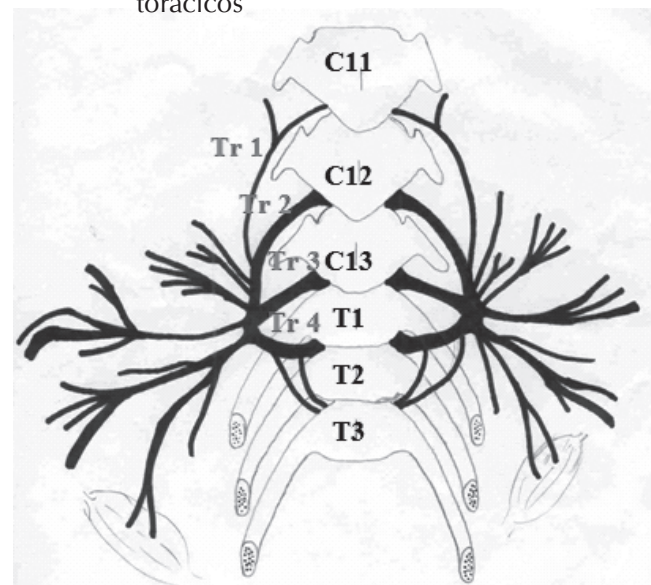

Figura 2 - Esquema mostrando que o plexo braquial do urubu (Coragyps atratus foetens) possui quatro troncos $(\operatorname{Tr} 1, \operatorname{Tr} 2, \operatorname{Tr} 3$ e $\operatorname{Tr} 4)$, os quais originam-se dos ramos ventrais dos nervos espinhais cervicais (C11, C12, C13) e dos ramos ventrais dos nervos espinhais torácicos (T1 e T2)

aves - 100\%; partem da margem cranial do cordão dorsal em ambos antímeros. Os ramos nervosos destes nervos são destinados unicamente aos músculos esternocoracóide, supracoracóide, subcoracóide, subescapular e escapulo-umeral dorsal.

O segundo tronco procede unicamente de $\mathrm{C} 12$ nos antímeros direito e esquerdo em 100\% dos casos, oferecendo ao cordão dorsal, o nervo axilar, como um ramo terminal desse cordão do plexo braquial, após ultrapassar a axila cranialmente ao nervo radial curva-se ao redor do

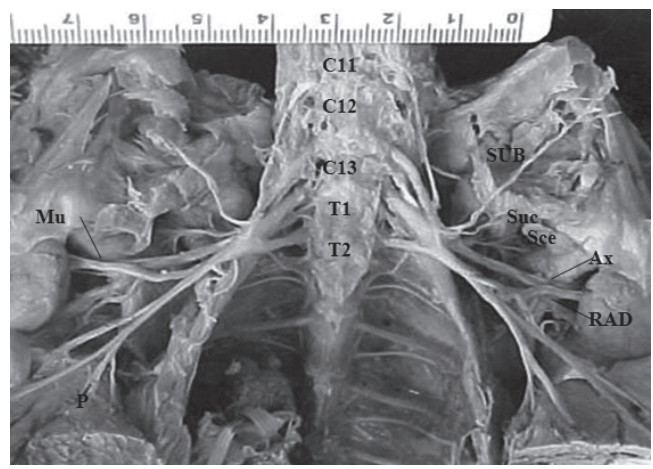

Figura 3 - Fotografia da face ventral da coluna vertebral na transição das regiões cervical e torácica identificando as raízes constituintes do plexo braquial no urubu (Coragyps atratus foetens) com os seguintes nervos: subescapular (SUB), supracoracóide (Suc), subcoracoescapular (Sce), axilar (Ax), radial (RAD), medianoulnar $(\mathrm{Mu})$, peitorais craniais e caudais $(\mathrm{P})$

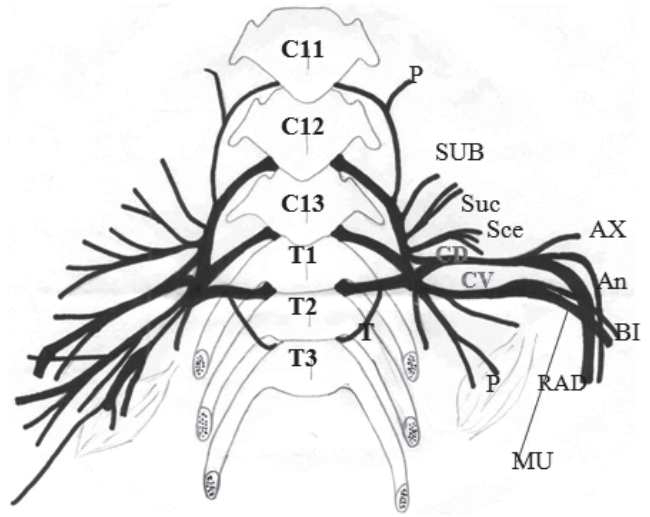

Figura 4 - Esquema mostrando os nervos provenientes do plexo braquial do urubu (Coragyps atratus foetens): peitorais cranial e caudal (P), subescapular (SUB), supracoracóide (Suc) subcoracoescapular (Sce), axilar (AX), radial (RAD), anconeal (An), bicipital (BI) medianoulnar (MU), torácico $(\mathrm{T})$, cordão dorsal (CD) e cordão ventral (CV)

músculo escapulo-umeral caudal. Este nervo estende-se dorsalmente através de uma abertura entre a superfície caudal da articulação escapulo-umeral e a margem proximal do músculo grande dorsal, entre as partes umeral e escapular do músculo tríceps braquial, bifurcando-se, oferece ramos aos músculos deltóide maior e menor. O nervo radial é o maior dos dois ramos terminais do cordão dorsal do plexo braquial, inerva os músculos da loja dos extensores do antebraço e da mão. O nervo 
anconeal surge da superfície caudal do nervo radial, e percorre por baixo, a superfície caudal do braço. O nervo radial continua seu percurso ao redor do úmero e penetra na fossa cubital, cranialmente à extremidade distal do músculo bíceps braquial profundamente ao músculo extensor radial do carpo, ao qual envia um espesso ramo. O tendão do músculo bíceps separa o nervo radial do nervo mediano e da artéria radial em todos os animais, em ambos os antímeros.

O terceiro tronco origina-se nos antímeros direito e esquerdo entre $\mathrm{C} 13 \mathrm{e} \mathrm{T} 1$, e o quarto tronco entre T1 e T2. T2 emite filamentos nervosos que se unem à raiz nervosa de T1. No antímero direito emite um filamento em cinco aves $(35,71 \%)$, e no esquerdo, seis aves $(42,85 \%)$. Em nove indivíduos $(64,29 \%)$, emite dois filamentos no antímero direito, enquanto no esquerdo, emite apenas dois filamentos em sete aves $(50 \%)$ e três ramos em um indivíduo $(7,15 \%)$ para T1, e este quarto tronco ao se unir com o segundo e terceiro tronco, originam o cordão ventral, e deles partem o nervo medianoulnar, o qual penetra no braço ventralmente ao músculo escapulotríceps; nesta porção situa-se cranialmente às partes proximais da artéria e veias braquiais.

O nervo medianoulnar percorre o braço profundamente, no sulco entre o músculo bíceps e o músculo escapulotríceps. O nervo bicipital, ao dobrar distalmente no braço, inerva o músculo coracobraquial cranial e emite um ramo proximal em todos os casos, tanto no antímero direito como no esquerdo. Parte do nervo atravessa a borda cranial do músculo e supre o músculo bíceps propatagial.

O nervo medianoulnar divide-se nos nervos mediano e ulnar, ao aproximar-se da fossa cubital nas 14 aves - 100\%, em ambos os antímeros. O nervo ulnar acompanha a artéria do mesmo nome na superfície ventral da articulação cubital, cruzando as origens dos músculos flexores superficiais, imediatamente após a veia correspondente. Inerva parte dos músculos flexores do antebraço, enquanto o nervo mediano supre a maioria dos músculos flexores ventrais do antebraço e os músculos intrínsecos da borda anterior da mão. $\mathrm{Na}$ fossa cubital, este nervo situa-se imediatamente ventral à artéria radial e ao tendão do músculo bíceps. Inerva o músculo braquial e a parte cranial da articulação cubital na totalidade das peças em ambos os antímeros. O cordão ventral, além de oferecer o nervo medianoulnar, origina os nervos peitorais em todos os casos nos antímeros direito e esquerdo. $\mathrm{O}$ nervo peitoral divide-se dentro do tórax nos nervos peitorais cranial e caudal inervando também o músculo coracobraquial caudal. Do quarto tronco (T1) procede os ramos intercostais, e todos os componentes emitidos desse tronco que chega ao (T2), se anastomosa com o nervo intercostal correspondente em todas as aves analisadas e em ambos os antímeros. De todos os nervos do plexo braquial, partem ramos que inervam a cútis designados nervos cutâneos, identificados em todos os urubus estudados em ambos antímeros.

\section{Discussão}

O estudo dos componentes do plexo braquial nas aves é importante não apenas como um conhecimento morfológico, o que na realidade já justificaria plenamente esta investigação, mas também face às alterações que os nervos podem sofrer em determinadas situações, como informam. ${ }^{8,11,15}$ Segundo estes autores na doença de Marek uma das manifestações clínica são os sintomas nervosos, com o aumento de volume dos nervos periféricos, perda de estrias, e queda da asa.

De fato, no urubu em todas oportunidades notou-se quatro troncos nervosos de maior calibre diretamente comprometidas na inervação do membro torácico destes animais especialmente no que se refere aos músculos flexores (ventrais) e extensores (dorsais), o que difere dos perus, os quais apresentam três troncos principais. ${ }^{21}$

Conforme a Nomina Anatomica Avium $^{19}$ os nervos espinhais são organizados 
semelhante àqueles dos mamíferos, assim o número e o nome destes nervos parecem não sofrer grandes alterações, mas é evidente uma simetria na distribuição periférica destes nervos suprindo a musculatura do membro torácico.

Os nervos espinhais são denominados nervos cervicais, torácicos, lombares, sacrais e coccígenos, cujo número corresponde geralmente ao número das vértebras de cada região e varia conseqüentemente entre as espécies de aves. ${ }^{14}$

Nickel, Schummer e Seiferle ${ }^{14}$ citam ainda que o primeiro nervo cervical (C1) emerge entre o osso occipital e a primeira vértebra cervical e o último nervo cervical deixa o canal espinhal entre a última vértebra cervical e primeira torácica. Neste trabalho adotamos procedimento idêntico situando cada um dos componentes do plexo braquial no urubu e observou-se cada um deles ocupando a transição intervertebral de C11 a T2. Já Moreira et al. ${ }^{21}$ observaram em seu estudo com perus, que cada um dos componentes deste plexo ocuparam a transição intervertebral de C12 a T2, a qual emitiam ramos a T3.

Estudos sobre o plexo braquial foram efetuados em pombos, especialmente sobre o nervo radial. ${ }^{12,13}$ Com alusão a este nervo, para Wang et al. ${ }^{18}$, as fibras nucleares durante o estímulo elétrico revelaram um tipo uniforme de resposta que consiste em uma inibição inicial seguida por uma excitação desobstruída do córtex cerebelar. Relatam ainda a convergência dos impulsos dos nervos aferentes que originam nas diferentes regiões do corpo dentro da mesma área do cérebro, atividade que pode ser importante para a integração dos movimentos do membro da ave, estas observações são importantes, pois o nervo radial tem importante papel na inervação dos músculos do membro torácico a serem utilizados durante o vôo, atividade intensa nestes animais.

Os nervos cervicais inervam, por meio de seu ramo dorsal, o grupo dorsal dos músculos curtos das junções da cabeça e a musculatura da nuca, enquanto seu ramo ventral vai ter à musculatura ventral do pescoço e Istmo das fauces. Os filamentos ventrais dos dois nervos cervicais conectam também com os filamentos dos nervos do hipoglosso. Embora estes nervos não estejam relacionados diretamente na composição do plexo braquial, são importantes na postura do corpo do animal durante o vôo. Os dois últimos nervos cervicais estão envolvidos na formação do plexo braquial podendo existir conexões entre os componentes do plexo braquial, em maior ou menor extensão. ${ }^{14}$

De acordo com a NAA ${ }^{19,20}$, o plexo braquial éo conjunto de nervos intercomunicantes que inerva o membro torácico. O plexo apresenta quatro raízes, as quais se unem para formar três troncos curtos, nos quais há um intercâmbio de fibras. Os troncos apresentam alguma separação em divisões dorsal e ventral que se combina para formar dois cordões nervosos. Ramos do cordão dorsal suprem músculos do compartimento dorsal (extensor) do membro e a pele sobrejacente; os ramos do cordão ventral (flexor) do membro. Os ramos terminais do cordão ventral são tronco peitoral e o nervo mediano-ulnar. O cordão dorsal emite o nervo axilar e continua dentro do braço como o nervo radial. A disposição encontrada no urubu, difere desta descrição no que se refere à formação dos cordões ventrais e dorsais, pois nesta ave o cordão dorsal é formado após a uniam das duas primeiras raízes enquanto o cordão ventral forma-se após a convergência das três últimas, esta observação é sempre caracterizada à esquerda e à direita. Nas aves os dois últimos nervos cervicais e os dois primeiros torácicos, ou primeiro, ou mesmo talvez os três primeiros nervos torácicos, são envolvidos na formação do plexo braquial. Nos patos e nos gansos os filamentos ventrais dos dois últimos nervos cervicais e dos dois primeiros nervos torácicos constituem o plexo braquial. O plexo braquial pode ser dividido em uma parte cranial e uma caudal. O plexo divide-se em quatro grupos: nervos torácicos dorsais; nervos torácicos ventrais; nervos braquiais dorsais e nervos braquiais ventrais. ${ }^{6,14}$ 
Particularizando o urubu, registramos que além de três troncos de calibre acentuado, representando os nervos C12, C13 e T1, participam do referido plexo $\mathrm{C} 11$, de forma constante de ambos os lados e em filete único, enquanto de T2 pode emergir 1, 2 ou 3 filetes à esquerda e 1 ou 2 filetes à direita, que se unem sempre a T1.

O nervo torácico dorsal inerva os músculos rombóide superficial e profundo e os músculos serrátil ventral e profundo.

O nervo torácico ventral inerva a musculatura supracoracóide, origina o nervo subescapular, assim como os músculos escapulo-umeral. Originam também os grandes nervos peitorais que inervam os músculos peitorais.

Um filamento do nervo braquial dorsal inerva os músculos longuíssimos do dorso, e um outro filamento, os nervos axilares, dando ramos para a pele do lado dorsal da asa e do ombro, o músculo deltóide, o músculo coracobraquial e os músculos propatagiais cervicais. $\mathrm{O}$ nervo ancôneo e o nervo radial são também parte deste grupo de nervos braquiais dorsais. Os filamentos do ancôneo, por meio de seu ramo profundo, o músculo tríceps braquial e o músculo ancôneo pelo ramo superficial. Os nervos radiais são filamentos grossos que inervam a cabeça do músculo umeral braquial e do músculo tríceps. $\mathrm{Na}$ junção do cotovelo o nervo radial emite um grande filamento ao músculo extensor carpo radial e o músculo supinador e um outro filamento à junção do próprio cotovelo. Aqui se divide em um ramo cranial e um ramo caudal. Ao longo de seu curso para a junção carpal o último emite ramo muscular para o músculo extensor carpo ulnar, o músculo extensor digital comum, o músculo epicôndilo-ulnar e numerosos filamentos pequenos secundários da asa. Os ramos craniais representam a continuação dos nervos radiais. Inerva o músculo abdutor longo do dedo, cruza a junção carpal e estende finalmente além do metacarpo às regiões dos dígitos. Ao longo de seu curso fornece o músculo extensor digital longo, os pequenos músculos do extensor na região do metacarpo emitindo ramos primários.

Os nervos braquiais ventrais incluem os nervos cutâneos braquial caudais, o nervo ulnar e o nervo mediano o qual é ligado com a primeira peça do nervo ulnar para dar origem ao nervo medioulnar. Este último nervo cruza o lado medial do úmero e dá origem a um filamento para o músculo coracobraquial e um filamento para o músculo bíceps braquial. No nível da junção do cotovelo os nervos ulnar e mediano separam-se e o nervo ulnar origina filamentos ao aspecto extensor da junção, dando origem aos filamentos dos músculos flexores ulnar do carpo, o qual se divide em ramos craniais e caudais. Os ramos caudais percorrem ao longo da superfície caudal do carpo e do metacarpo e assim alcança as pontas dos dígitos. Os ramos craniais são a continuação do nervo ulnar que inerva o músculo flexor digital superficial e parte dos pequenos músculos flexores do metacarpo. O nervo mediano cruza a junção do cotovelo e assim, ganha a superfície medial do braço e do metacarpo mais para baixo. Da origem aos nervos cutâneos, um filamento para o músculo flexor carpo radial, o ramo musculocutâneo para o músculo pronador, originando filamentos musculares, um para o músculo metacarpo ulnar ventral, para o músculo flexor digital superficial e profundo, e também fornecem pequenos filamentos para os pequenos músculos do metacarpo. ${ }^{14}$ Os informes que obtivemos no urubu, em linha gerais não se afastam destas considerações, evidentemente devese atentar para o fato de que nesta ave as raízes nervosas componentes do plexo braquial são em menor número.

Neste sentido completam os informes de $\mathrm{Buhr}^{7}$, Holland et al. ${ }^{9,10}$, Parker e George ${ }^{22}$, Smith, Quist e Crum ${ }^{17}$, importantes pois permitem conhecer o plexo braquial das aves, além de facilitar os diagnósticos de disfunções neuromusculares, conseqüentes de processos traumáticos, 
infecções, neoplasias e infestações por ácaros e vírus, sobre as características pósmorte dos músculos peitorais, como também pelos procedimentos anestésicos local ou regionais, que objetivam potencializar o efeito analgésico durante o período pré e trans-operatório em uma tentativa de determinar o papel funcional das fibras nervosas durante o vôo.

Assim, analisando as raízes ventrais nervosas que contribuem para a formação do plexo braquial do urubu, constata-se que nestes animais partem quatro troncos da medula espinhal semelhante aos observados nas galinhas, pombos, patos e gansos. ${ }^{6,14,20}$

\section{Conclusões}

O estudo de 14 urubus adultos machos e fêmeas, permite estabelecer que: o plexo braquial nestas aves situam-se na transição entre as regiões cervical e torácica entre C11 a T2; os nervos componentes do plexo braquial nestes animais são constituídos por quatro raízes dos nervos espinais, a primeira e a última mais delgadas, a segunda, a terceira e a quarta mais calibrosas; os nervos neste plexo convergem para constituírem dois cordões nervosos, o dorsal correspondente aos músculos extensores e o ventral correspondente aos músculos flexores.

\section{The arragement of configurat of nervs of brachial plexus in vulture (Coragyps atratus foetens - Linnaeus, 1758)}

\section{Abstract}

The anatomical study of the origin and distribution of brachial plexus in vulture (Coragyps atratus foetens) was performed in 14 animals, adults, males and females, deriving of the region of Araçatuba (SP). After fixed in watery solution of formaldehyde $10,00 \%$, became dissected bilateral of the origin of the brachial plexus, and yours distribution. The analysis allowed verify that brachial plexus of vulture, four root possess, which originate from the ventral branches of cervical spinal nerves eleven (C11), twelve (C12) and thirteen (C13) and of the ventral branches of thoracic spinal nerve one (T1) and (T2) in both sides (100\%). The first root part of C11 in the right and left side, and of the edge skull of the dorsal lace the nerves subescapular, subcoracoescapular e supracoracóide in both antímeros $(100 \%)$. As the root originates from C12 in both sides, giving origin to the dorsal lace, giving the axilar, radial and anconeal nerves $(100 \%)$. The third root of plexus originates solely from C13 $(100 \%)$ and the root of $\mathrm{T} 1 \mathrm{in}$ both sides (100\%). The roots of C12, C13 and T1 was united the ventral lace originates, which breaks the nerves to medianoulnar that divided in medium and to ulnar and the pectoral nerves $(100 \%)$. T2 emits filaments that join it root nervous of T1, being one filament $(35,55 \%)$ and two filaments $(64,29 \%)$ in side right, while that in the left one filament (42,85\%), two filaments $(50 \%)$ and three filaments $(7,15 \%)$.

\section{Referências}

1 KING, A. S. Introdução as aves. In: GETTY, R. Sisson/ Grossman: anatomia dos animais domésticos. 5. ed. Rio de Janeiro: Interamericana, 1981. v. 2, p. 16771679.

2 ROMER, A. S.; PARSONS, T. S. Quem é quem entre os vertebrados. In: Anatomia comparada dos vertebrados. 5. ed. São Paulo: Atheneu, 1985. p. 29-80.
Key words:

Brachial plexus.

Neuroanatomy.

Vulture.

Coragyps atratus foetens.
3 STORER, T. I.; USINGER, R. L.; STEBBINS, R. C.; NYBAKKEN, J. W. Zoologia geral. 6. ed. São Paulo: Companhia Editora Nacional, 2000. p. 674-675.

4 SOUZA, W. M.; CARVALHO, R. G.; SOUZA, N. T. M; MIGLINO, M. A. Estudo anatômico das artérias da base do encéfalo no urubu (Coragyps atratus foetens). Brazilian Journal of Morphological Sciences, v. 17, p. 210, 2000. Supplement.

5 INTERNATIONAL COMMITTEE ON AVIAN ANATOMICAL NOMENCLATURE. Nomina anatomica 
avium. London: Academic Press, 1979. 637 p.

6 BAUMEL, J. J. Sistema nervoso das aves. In: GETTY, R. Sisson/Grossman: anatomia dos animais domésticos, 5. ed. Rio de Janeiro: Interamericana, 1981. v. 2, p. 1890-1930

7 BUHR, R. J. Selective denervation of the Musculus pectoralis muscle in the chicken. Poultry Science, $\mathrm{v}$. 69 , n. 1, p. 124-132, 1990.

8 DYCE, J. M.; SACK, W. O.; WENSING, C. I. G. Anatomia das aves. In:__. Tratado de anatomia veterinária. Rio de Janeiro: Guanabara Koogan, 1990. p. 537-554.

9 HOLLAND, M. S.; MACKENNZIE, C. D.; BULL, R. W.; SILVA, R. F. A comparative study of histological conditions suitable for both immunofluorescence and in situ hybridization in the detection of Herpesvirus and its antigens in chicken tissues. Journal of Histochemistry and Cytochemistry, v. 44, n. 3, p. 259265, 1996.

10 HOLLAND, M. S.; MACKENNZIE, C. D.; BULL, R. W.; SILVA, R. F. Latent turkey herpesvirus infection in lymphoid, nervous, and feather tissues of chickens. Avian Diseases, v. 42, n. 2, p. 292-299, 1998.

11 KUIKEN, T.; WOBESER, G.; LEIGHTON, F. A.; HAINES, D. M.; CHELACK, B.; BOGDAN, J.; HASSARD, L.; HECKERT, R. A.; RIVA J. Pathology of Newcastle disease in double-crested cormorants from Saskatchewan, with comparison of diagnostic methods. Journal of Wildlife Diseases, v. 35, n. 1, p. 8-23, 1999.

12 NECKER, R.; NEUMANN, V. Response characteristics of cerebellar nuclear cells in the pigeon. Neuroreport. v. 8, n. 6, p. 1485-1488, 1997.

13 NECKER, R.; SCHERMULY, C. Central projections of the radial nerve and of one of its cutaneous branches in the pigeon. Neuroscience Letters, v. 58, n. 3, p. 271276, 1985.

14 NICKEL, R.; SCHUMMER, A.; SEIFERLE, E. Peripheral nervous system. In: Anatomy of the domestic birds. Berlin: Parey, 1977. p. 131-139.

15 SALLE, C. T. P. Aspectos atuais da doença de Marek em poedeiras. In: SIMPÓSIO TÉCNICO DE PRODUÇÃO DE OVOS, 3.,1993, São Paulo. Anais...São Paulo, 1993. v. 1.

16 SHELL, L.; RICHARDS, M.; SAUNDERS, G. Brachial plexus injury in two red-tailed hawks (Buteo jamaicensis). Journal of Wildlife Diseases, v. 29, n. 1, p. 177-179, 1993.

17 SMITH, K. E.; QUIST, C. F.; CRUM, J. M. Clinical illness in a wild turkey with Laminosioptes cysticola infestation of the viscera and peripheral nerves. Avian Diseases, v. 41, n. 2, p. 484-489, 1997.

18 WANG, B.; DENG, C.; ZHAO, Y.X.; HU, C.H. Projection of afferent impulses from the brachial plexus and sciatic nerve to the corpus striatum in pigeons. Sheng Li Xue Bao, v. 41, n. 2, p. 120-127, 1989.

19 INTERNATIONAL COMMITTEE ON VETERINARY GROSS ANATOMICAL NOMENCLATURE. Nomina anatomica veterinaria. 4. ed. New York: World Association on Veterinary Anatomist, 1994. 198 p. (Together with nomina histologica, 2. ed. 1992 and nomina embryologica veterinaria, 1992).

20 DUBBELDAM, J. L. Systema nervosum periphericum. In: BAUMEL, J.J. Handbook of avian anatomy: nomina anatomica avium. 2. ed. Cambridge: Nuttall Ornithological Club, 1993. p. 555-584.

21 MOREIRA, P. R. R.; SOUZA, W. M.; SOUZA, N. T. M.; CARVALHO, R. G.; CUSTÓDIO, A. A. Arranjos configurados pelos nervos do plexo braquial no peru (Meleagris gallopavo - LINNAEUS, 1758). ARS Veterinária, v. 21, n. 3, p. 296-302, 2005.

22 PARKER, G. H.; GEORGE, J. C. Effects of short and long term exercise on intracellular glycogen and fat in pigeon pectoralis. Japan Journal of Physiology, v. 25, n. 2, p. 175-184, 1975. 